\title{
Use of Fly Ash to Treat Acid Mine Drainage Before Use in Backfill Operations
}

\author{
V.G. Fester Cape Peninsula University of Technology, South Africa \\ P.T. Slatter Cape Peninsula University of Technology, South Africa \\ V.R.K. Vadapalli University of the Western Cape, South Africa
}

L. Petrik University of the Western Cape, South Africa

\begin{abstract}
Large quantities of fly ash (FA) are generated annually in South Africa and some of it is used in backfill operations. However, this waste can also be used to treat acid mine drainage (AMD,) another waste stream commonly found in the minerals industry. Particle size distribution (PSD) of FA plays an important role in the AMD treatment quality and viscosity of the residual solids that can be used directly for backfill purposes. In this study, we have investigated the behaviour of two types of FA in treating AMD as well as the rheology of the resulting paste. Small-scale studies were first carried out in the laboratory where the rheology was determined using a rheometer as well as larger-scale pipe tests. Chemistry studies indicated that the higher fines fraction enhances the treatment of $A M D$ by reducing the time taken to reduce the $p H$ to a minimum of 7. However, it was found with the two different types of FA tested, increasing the coarse fraction results in higher viscosity than when the fines fraction is increased. Similar behaviour was found in previous studies but the viscosity increase was attributed to changes in $\mathrm{pH}$. However, this study shows that there may be some truth in the controversial effect of coarse particles on the rheology of suspensions.
\end{abstract}

\section{Introduction}

FA is a coal combustion by-product from power stations. It is highly alkaline in nature and is an environmental hazard related to energy generation which has received much attention of late. Only 5\% of the FA that is produced in South Africa is gainfully utilised, and the rest is dumped in ash dams and landfills (Eskom, 2001). Poor management of FA causes various environmental problems such as loss of usable land, as well as detrimental effects on plants and soil, air pollution and aesthetics (Carlson and Adriano, 1993). There is mounting pressure on power stations to manage their FA in an effective manner that is beneficial to the environment. FA from South African power stations has been used successfully to treat/neutralise AMD (Gitari et al., 2006). AMD is a consequence of the oxidation of sulfide bearing minerals which are exposed to the environment, mainly by mining and smelting activities. AMD is highly acidic (pH 2-4) and carries a high load of heavy metals and sulphates with it (Razo et al., 2004). The insoluble solid residues (SR) that were obtained as a result of the reaction between FA and AMD proved suitable as a backfill material to stabilise mining activities (Petrik et al., 2006a).

The particle size distribution (PSD) of a particular FA varies with time, depending on the coal burning conditions in the power stations. Such variability in the PSD of FA could influence its capability to neutralise AMD and sequester toxic metals. Moreover, it could also influence the rheological properties of the resultant SR paste. Rheological investigation of SR will elucidate certain critical parameters such as optimum solids to liquid ratio, yield stress, hydraulic gradient, etc. to transport SR to the backfill site. Understanding the rheology of SR is critical to the design and optimisation of the hydraulic transportation system.

Neutralisation experiments were carried out using standard FA and FA altered with respect to its fine and coarse particle content, to understand the effect of PSD on the neutralisation kinetics. The SR recovered after these experiments were investigated for their rheological behaviour and also to understand the influence of the PSD of FA on the rheology of SR, and the results are presented and discussed in this paper. 


\section{Effect of particle size distribution on the neutralisation capacity of FA}

The FA from Arnot power station in South Africa was used for this study. This standard sample of fly ash was altered to increase the volume of fines $(>25 \mu \mathrm{m})$ and coarse $(75-150 \mu \mathrm{m})$ fraction before the neutralisation. PSD analysis showed that the FA particle size distribution was $<25 \mu \mathrm{m}$ (38\%), 25-75 $\mu \mathrm{m}$ (42\%) and 75-150 $\mu \mathrm{m}$ (14\%). The percentage of fine and coarse particles (in the context of this study) could influence the neutralisation capacity of FA. Therefore, the original FA was compared with samples that were prepared by fine or coarse particle addition to double the $<25 \mu \mathrm{m}$ or the $75-150 \mu \mathrm{m}$ fractions. AMD from Landau mine was reacted with un-altered (original) FA and two altered FAs that were doubled with respect to the mass \% of their fine and coarse fractions. The above FA (both the standard and enriched samples) was reacted with $\mathrm{AMD}$ at a ratio of 1:3. The $\mathrm{pH}$ and electrical conductivity of each reaction was monitored every half hour until the mixture reached a $\mathrm{pH}$ of 7 or greater. The original AMD and process waters recovered from different reactions were analysed for metal and sulphate concentrations using Inductive Couples Plasma Mass Spectrometer (ICP-MS) and Ion Chromatography (IC) respectively. The original FA, two altered FA and solid residues recovered from the reactions were examined for major oxides using $\mathrm{X}$-ray fluorescence (XRF).

\subsection{Particle size distribution of FA}

Figure 1 shows the particle size distribution obtained using a Malvern 2000 particle sizer and the results are tabulated in Table 1 showing the percentage of fine and coarse particles in each of the FA mixtures prepared. The density of the FA particles was $2200 \mathrm{~kg} / \mathrm{m}^{3}$. The samples are described in terms of the volume percentage of fines as shown in Figure 1.

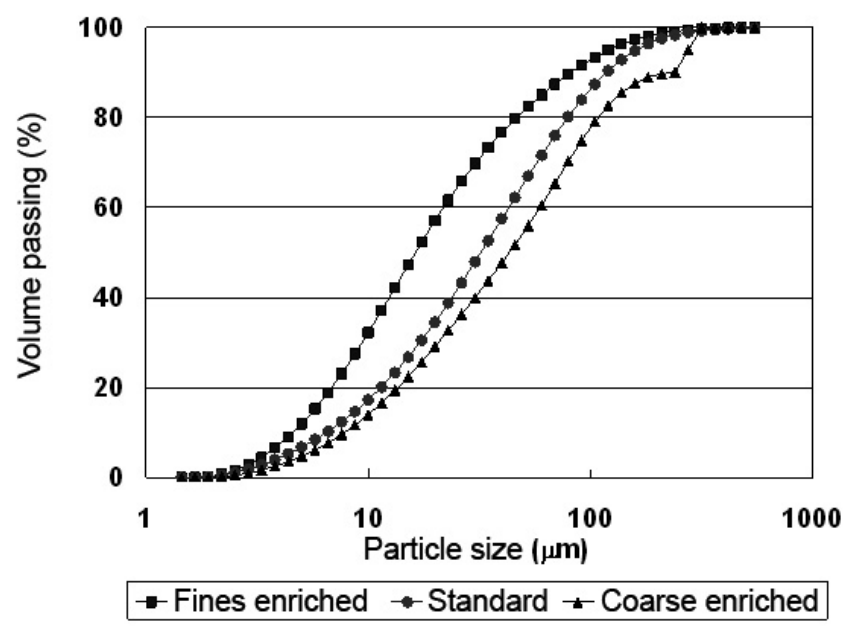

Figure 1 Volume \% particle size distribution plot of standard and modified ash

Table 1 Percentage of fine and coarse particles in different FA

\begin{tabular}{lcc}
\hline \multicolumn{1}{c}{ FA } & \% Fines & \% Coarse \\
\hline Normal & 38 & 14 \\
FA enriched with fines & 76 & 5.4 \\
FA enriched with coarse & 32 & 28 \\
\hline
\end{tabular}

\subsection{Effect of particle size distribution on electrical conductivity and $\mathrm{pH}$}

Figure 2 gives a clear indication of $\mathrm{pH}$ and electrical conductivity (EC) trends of different neutralisation reactions. Although no significant difference is observed in the EC values between the three reactions, it is quite apparent that the time of reaction to reach alkaline $\mathrm{pH}$ was the fastest when using $\mathrm{FA}$ enriched with fines, followed by the reactions that used normal FA and coarse FA. 


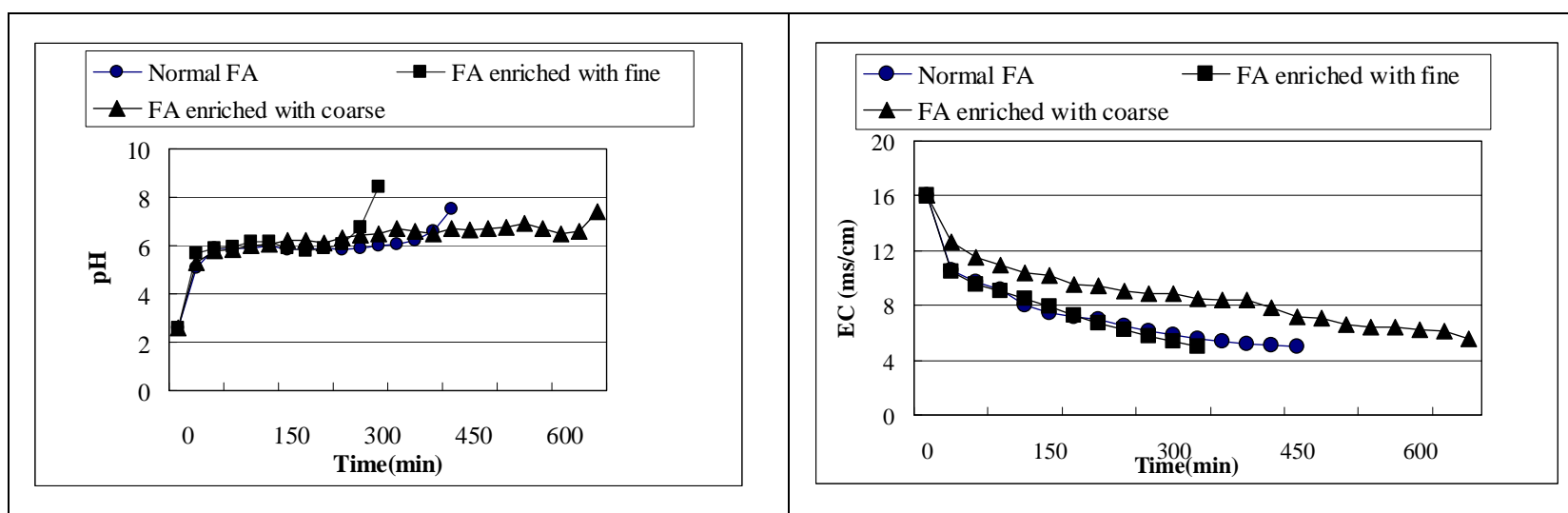

Figure $2 \mathrm{pH}$ and EC trends of different neutralisation reactions that used different FA

\subsection{ICP-MS and XRF results}

Table 2 shows the XRF analysis of the unaltered Arnot FA; altered Arnot FA enriched with respect to fine or coarse particles and solid residues recovered from the different neutralisation reactions that used the above mentioned FA. Although the differences are generally low, it is evident from the above table that the mass percentage of most of the major oxides such as $\mathrm{Al}_{2} \mathrm{O}_{3}, \mathrm{CaO}, \mathrm{Cr}_{2} \mathrm{O}_{3}, \mathrm{Fe}_{2} \mathrm{O}_{3}, \mathrm{~K} 2 \mathrm{O}, \mathrm{MgO}$ and $\mathrm{TiO}_{2}$ is more in the FA that is enriched with fine particles when compared to the normal FA and FA enriched with coarse particles. The enrichment of Fe in all the solid residues indicates their efficiency to remove iron from the AMD. It can also be noticed that minor amounts of major oxides such as $\mathrm{SiO}_{2}, \mathrm{Al}_{2} \mathrm{O}_{3}$ and $\mathrm{CaO}$ were also utilised during the neutralisation reactions. The results also indicate that the main mechanisms that control the removal of metals from AMD are ion adsorption, precipitation and co-precipitation. Similar conclusions were made by Komnitas et al., 2004 while cleaning acidic leachates using FA barriers. Table 3 gives a clear picture of the efficiency of each FA to remove toxic elements from AMD. Figure 6 graphically represents and compares the efficiency of different FA to remove toxic elements and sulphate from AMD.

Table 2 XRF analysis for different FA and SR recovered from different reactions

\begin{tabular}{ccccccc}
\hline $\begin{array}{c}\text { Oxide } \\
(\mathbf{w} / \mathbf{w} \text { \%) }\end{array}$ & Arnot FA & SR-Arnot FA & Arnot FA+EF & SR-EF & Arnot FA+EC & SR-EC \\
\hline $\mathrm{SiO}_{2}$ & 53.69 & 49.79 & 53.81 & 49.12 & 53.86 & 51.25 \\
$\mathrm{Al}_{2} \mathrm{O}_{3}$ & 25.55 & 24.30 & 27.19 & 25.18 & 25.093 & 24.47 \\
$\mathrm{CaO}$ & 6.641 & 6.047 & 6.682 & 5.969 & 6.502 & 6.197 \\
$\mathrm{Cr}_{2} \mathrm{O}_{3}$ & 0.053 & 0.048 & 0.063 & 0.061 & 0.046 & 0.045 \\
$\mathrm{Fe}_{2} \mathrm{O}_{3}$ & 3.837 & 5.324 & 3.947 & 5.153 & 3.751 & 5.252 \\
$\mathrm{~K}_{2} \mathrm{O}$ & 0.587 & 0.559 & 0.615 & 0.555 & 0.603 & 0.565 \\
$\mathrm{MgO}$ & 2.600 & 2.201 & 2.668 & 2.421 & 2.565 & 2.271 \\
$\mathrm{MnO}$ & 0.055 & 0.11 & 0.050 & 0.13 & 0.057 & 0.11 \\
$\mathrm{NiO}$ & 0.010 & 0.0090 & 0.011 & 0.012 & 0.0080 & 0.0090 \\
$\mathrm{P}_{2} \mathrm{O}_{5}$ & 0.302 & 0.274 & 0.360 & 0.328 & 0.280 & 0.281 \\
$\mathrm{TiO}_{2}$ & 1.610 & 1.468 & 1.742 & 1.547 & 1.577 & 1.506 \\
\hline
\end{tabular}

SR-Arnot FA: Solid residues obtained from the reaction between un-altered FA and AMD; Arnot FA+EF: Altered Arnot FA enriched with fines; SR-EF: Solid residues obtained from the reaction between FA enriched with fines and AMD; Arnot FA+EC: Altered Arnot FA enriched with coarse; SR-EC: Solid residues obtained from the reaction between FA enriched with coarse and AMD. 
Table 3 ICP analysis of raw AMD and process waters from different reactions (in $\mathrm{mg} / \mathrm{L}$ )

\begin{tabular}{ccccc}
\hline Element & Landau AMD & Process water-NF & Process water-EF & Process water-EC \\
\hline $\mathrm{Zn}$ & 2.100 & 0.0080 & 0.0000 & 0.0070 \\
$\mathrm{~Pb}$ & 0.21 & $<0.010$ & $<0.010$ & $<0.010$ \\
$\mathrm{Ni}$ & 0.373 & 0.173 & 0.00200 & 0.0600 \\
$\mathrm{Mn}$ & 238.8 & 127.9 & 14.83 & 98.74 \\
$\mathrm{Fe}$ & 6540 & 0.5940 & 0.09200 & 0.1270 \\
$\mathrm{Co}$ & 0.637 & 0.324 & 0.008 & 0.106 \\
$\mathrm{Cd}$ & 0.001 & 0.001 & 0.001 & 0.001 \\
$\mathrm{As}$ & 0.006 & 0.006 & 0.006 & 0.006 \\
$\mathrm{Ag}$ & 0.005 & 0.005 & 0.005 & 0.005 \\
$\mathrm{Al}$ & 693 & 0.100 & 0.693 & 0.0310 \\
$\mathrm{SO}_{4}{ }^{2-}$ & 16452 & 5158 & 4401 & 5244 \\
\hline
\end{tabular}

- Process water-EF: Water recovered from the neutralisation Reaction with FA enriched with fines

- Process water-EC: Water recovered from the neutralisation Reaction with FA enriched with coarse

- Process water-NF: Water recovered from the neutralisation Reaction with unaltered FA

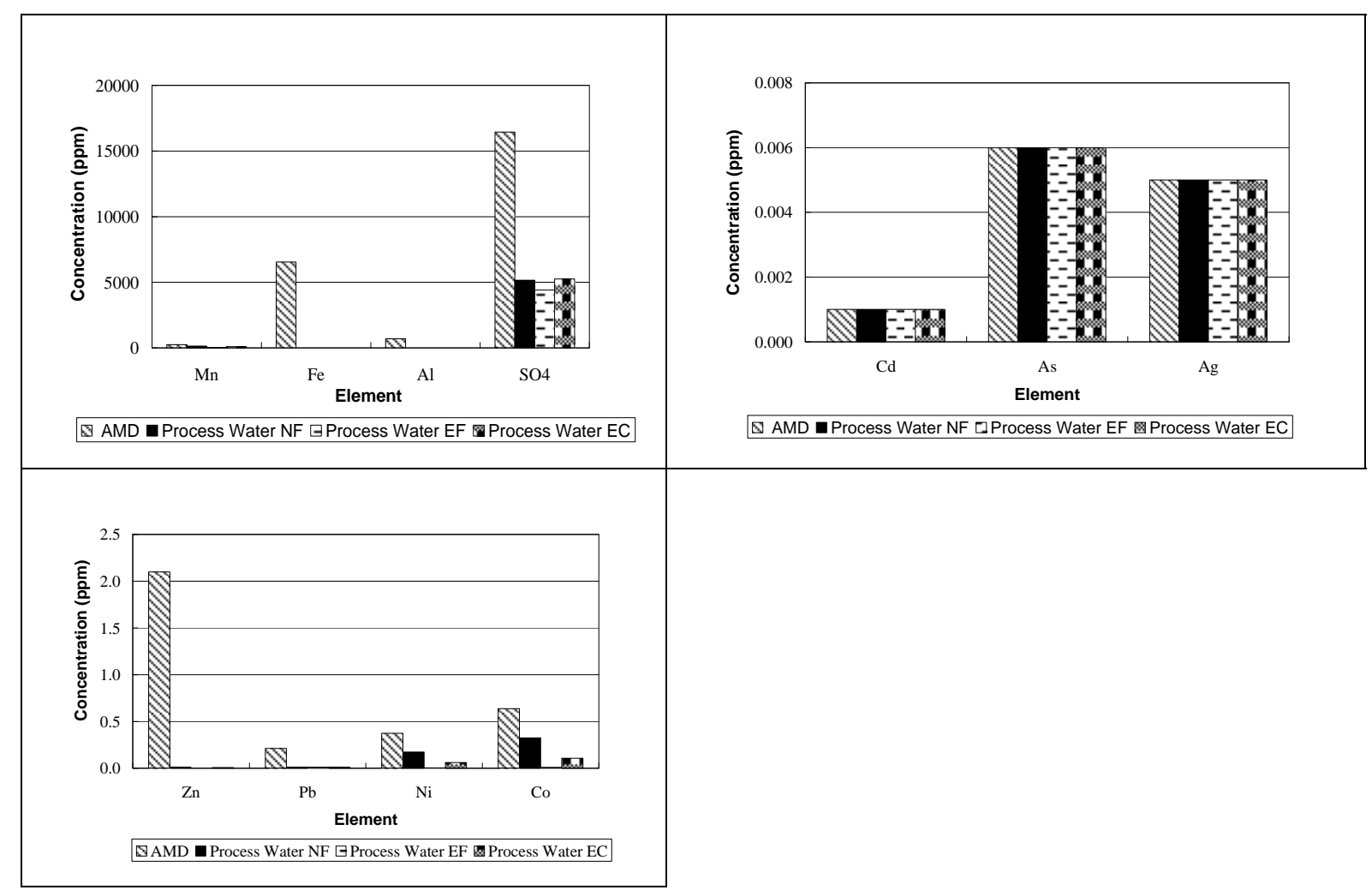

Figure 3 Toxic element removal efficiencies of different size fractions of FA

The reaction that used FA that was enriched with fines was more efficient in removing elements such as Ni, $\mathrm{Mn}, \mathrm{Fe}$ and $\mathrm{Co}$ and sulphate concentrations from AMD than the FA enriched with coarse size fractions. This can be attributed to the higher surface area of fine particles which has a greater reactive surface. Interestingly, the reaction that used FA that was doubled with respect to the mass \% of coarse particles achieved a better removal efficiency compared to the neutralisation reaction that used normal FA. This is 
probably due to the longer time taken by the reaction that used FA enriched with coarse particles to reach alkaline $\mathrm{pH}$. This would have allowed more time for the adsorption and precipitation reactions involved in the removal of the metals than in the case of the unaltered FA. This indicates that the removal efficiency of toxic elements by FA depends not only on the surface area but also on other factors such as contact time and mineralogy. Similar conclusions were made by Hakan et al. (2006) while studying the factors that influence the adsorption capacity of metals on zeolites.

\section{Effect of particle size distribution on rheology of residual solids}

Although some work has been done on the rheology of FA elsewhere (Cyr et al., 2000; Iyer and Stanmore, 1999; 2000; Heywood et al., 1993; Bournonville and Nzihou, 2002), the rheology of the residual solids obtained from the neutralisation process has not been reported yet. The rheological behaviour of suspensions is susceptible to small changes in particle size, particle size distribution, $\mathrm{pH}$ and concentration amongst other factors. However, when the FA is used to treat AMD, the resulting residual solids particle shape and distribution is significantly altered during the neutralisation process (Petrik et al., 2006d). It is therefore important to study the effect of the neutralisation process on the rheological behaviour of the residual FA paste in order to establish the design criteria for transport and backfilling. The particle size distribution of the FA can vary from batch to batch and its effect on the rheology and hence the pressure gradient during pipeline transport needs to be established.

\subsection{Rheometer results}

The residual solids from the Arnot ash were tested in an MC1 rheometer, using a standard cup-and-bob geometry. For high concentrations, the bob was replaced with a vane in an infinite sea geometry was used. The preliminary study shows that the particle size distribution has a significant effect on the rheology and the hydraulic gradient. The critical volume fraction obtained was 0.4 for all FA samples prepared, after which the yield stress increases exponentially with increasing volume fraction. From the samples prepared, it was shown that the maximum packing fraction was $46 \%$, above which hydraulic gradients become impractically high. The results obtained show that it is not just the effect of fines, but possibly an interaction or combination of fine and coarse particles. In this case, the addition of coarse particles did not decrease the viscosity as anticipated, but increased the viscosity, shear stresses and pumping head at concentrations greater than $42 \%$. It appears from the results that there is a cross-over point at a concentration of $41 \%$ where the coarse enriched suspension changes from being less viscous to more viscous than the standard sample as shown in Figure 4. Heywood et al. (1993) reported a similar case but attributed it to the difference in pH. In this case, the $\mathrm{pH}$ was 7.54 and 7.87 for the standard and coarse enriched suspension respectively. So it can be assumed that the coarser particles have an adverse effect on the viscosity and this anomaly should be investigated further (Ohlero and Ferreira, 2004). According to Cyr et al. (2000), any suspension can show shear thickening behaviour if the volume fraction is high and the suspension is non-flocculated. The other parameters that mostly contribute to shear thickening behaviour are particle shape, size and distribution. 


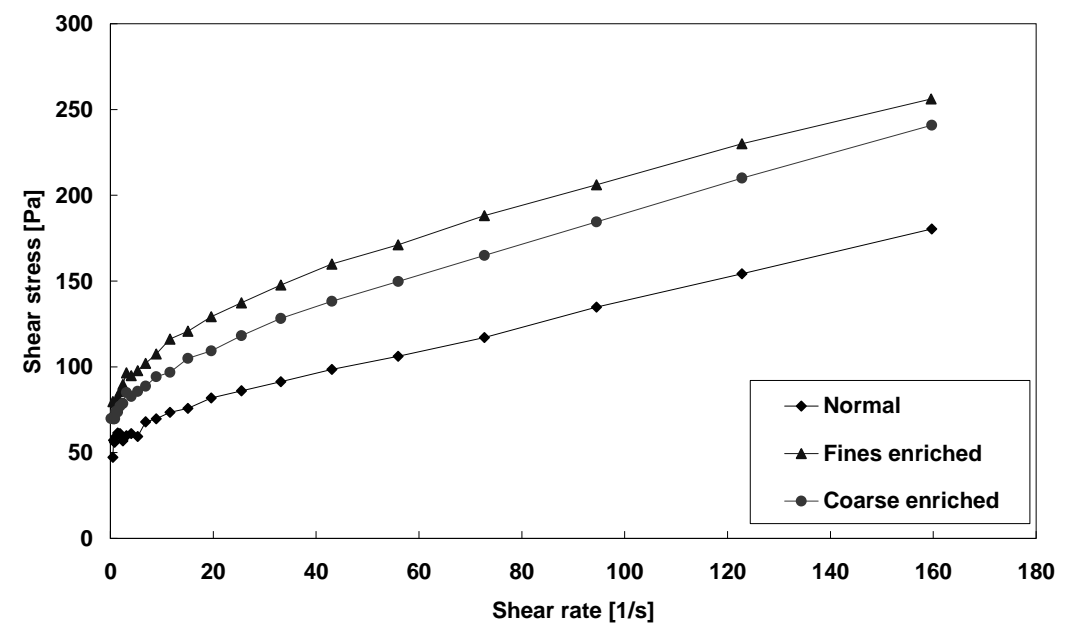

Figure 4 Effect of fines at a volume fraction $\phi=0.41$

\subsection{Pipe test results}

To ensure that the results obtained in the rheometer with the coarser slurries was not due to artefacts produced by the rheometer, another series of tests was conducted in a pipe rig. The pipe rig consisted of a positive displacement pump, a mass flow meter, a set of 16, 13 and $9 \mathrm{~mm}$ pipes across which the pressure was measured using pressure transducers.

\subsection{Ash characteristics}

This time, ash from a different power station was used that was fractionised as given in Figure 5. The Pozzfill is the standard ash obtained from the power station with a $d_{50}$ of $64.7 \mu \mathrm{m}$. Superpozz consisted mainly of the fines fraction of the Pozzfill. Approximately $98 \%$ was smaller than $20 \mu \mathrm{m}$ and a d $\mathrm{d}_{50}$ of $6.3 \mu \mathrm{m}$. A quantity of Pozzfill and superpozz was mixed to obtain a mixture with a $d_{50}$ of $16 \mu \mathrm{m}$. Figure 5 shows the particle size distribution of the ash.

Table 4 Summary of particle size distribution of Letabo ash slurries

\begin{tabular}{lcccccccc}
\hline Material & $\mathbf{d 1 0}$ & $\mathbf{d 5 0}$ & $\mathbf{d 9 0}$ & $\mathbf{< 1 0} \mathbf{~ u m}$ & $\mathbf{< 2 0} \mathbf{~ u m}$ & $<\mathbf{1 0 0} \mathbf{~ u m}$ & $>\mathbf{2 0}<\mathbf{1 0 0} \mathbf{~ u m}$ & $>\mathbf{1 0 0 u m}$ \\
\hline Pozzfill & 7.9 & 64.7 & 279 & 15.02 & 26.1 & 64.3 & 38.2 & 35.7 \\
$50 / 50$ & 3.97 & 16.0 & 221.2 & 45.5 & 59.3 & 74.3 & 15 & 25.7 \\
Superpozz & 2.98 & 6.33 & 14.3 & 81.8 & 97.9 & 99.57 & 1.67 & 0.43 \\
\hline
\end{tabular}




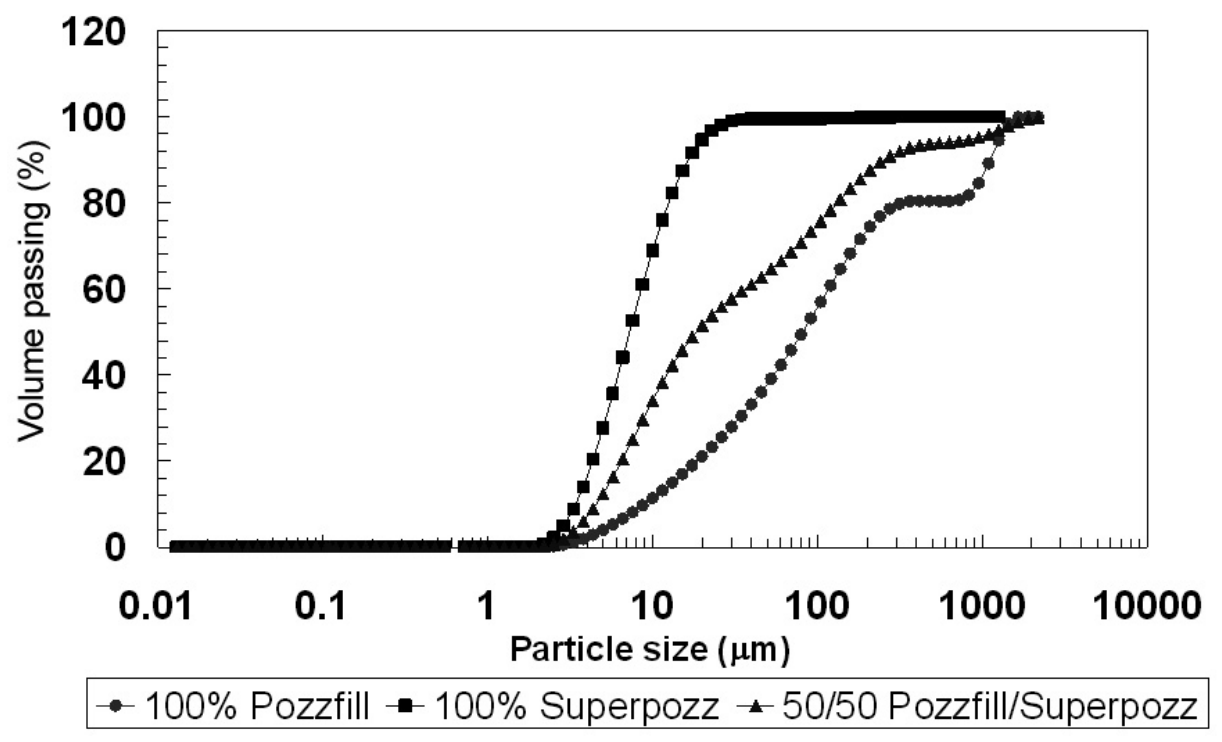

Figure 5 Particle size distribution of Letabo ash slurries

\subsection{Lethabo ash}

To investigate the effect of particle size distribution on the rheology of the ash, slurries were prepared using the Pozzfill slurry with additional fines fractions from the Superpozz fraction and ultimately testing a $100 \%$ Superpozz slurry with almost $98 \%$ of particles less than $20 \mu \mathrm{m}$. All the ash slurries were tested for three concentrations.

\subsection{Pozzfill (100\%)}

The Pozzfill is the 'standard ash' obtained from the mine. The physical and chemical properties of the Pozzfill ash slurry of three different concentrations are given in Table 5. A maximum solids concentration of $67 \%$ by weight was obtained after allowing settling overnight. It displayed Bingham plastic behaviour (Figure 6). The yield stress for the maximum concentration was 2.6 Pa.

Table 5 Lethabo Pozzfill (100\%) ash properties

\begin{tabular}{lccc}
\hline Property & $\begin{array}{c}\text { Lethabo } \\
\text { Pozzfill 1 }\end{array}$ & $\begin{array}{c}\text { Lethabo } \\
\text { Pozzfill 2 }\end{array}$ & $\begin{array}{c}\text { Lethabo } \\
\text { Pozzfill 3 }\end{array}$ \\
\hline Moisture [\%] & 33.30 & 39.02 & 43.63 \\
Density [kg/m $]$ & 1.563 & 1.487 & 1.446 \\
$\mathrm{Cw}[\%]$ & 66.70 & 60.98 & 56.37 \\
$\mathrm{Cv}[\%]$ & 46.92 & 40.58 & 37.17 \\
$\mathrm{pH}$ & 9.120 & 9.190 & 8.810 \\
$\mathrm{EC}[\mathrm{mS} / \mathrm{cm}]$ & 1.050 & 1.720 & 1.990 \\
$\tau_{\mathrm{y}}[\mathrm{Pa}]$ & 2.60 & 1.36 & 0.460 \\
$\mathrm{~K}\left[\mathrm{~Pa} . \mathrm{s}^{\mathrm{n}}\right]$ & 0.021 & 0.011 & 0.0070 \\
$\mathrm{n}$ & 1.000 & 1.000 & 1.000 \\
\hline
\end{tabular}




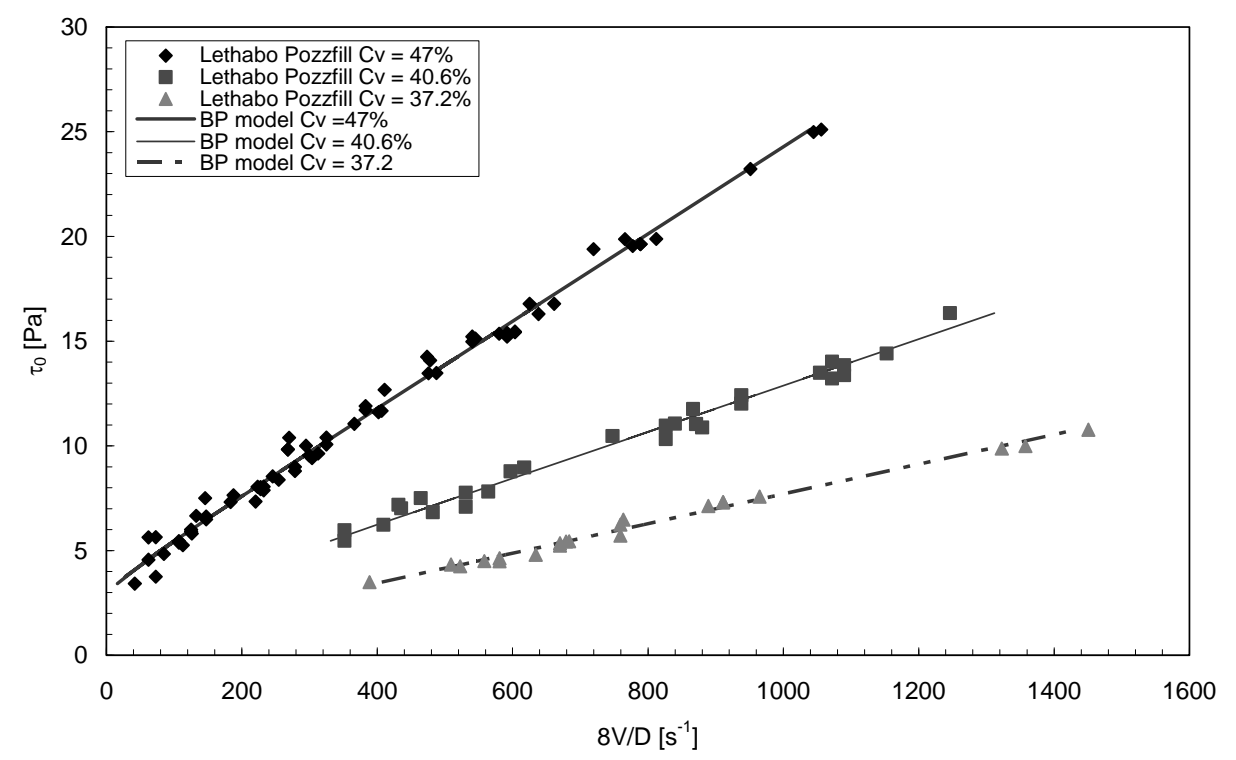

Figure 6 Pseudo-shear diagram for Lethabo Pozzfill (100\%) ash slurries

\subsection{Pozzfill/Superpozz 50/50}

In this case, the particle size distribution was altered by the addition of Superpozz to double the fraction less than $20 \mu \mathrm{m}$. The ash slurry properties are given in Table 6 . The actual results obtained were that it was altered from 26 to 59\%. The $d_{50}$ was changed to $16 \mu \mathrm{m}$. This slurry also displayed Bingham plastic behaviour (Figure 7). The yield stress for the maximum concentration was $3.5 \mathrm{~Pa}$.

Table 6 Lethabo Pozzfill/Superpozz (50/50) ash properties

\begin{tabular}{lccc}
\hline Property & $\begin{array}{c}\text { Lethabo } \\
\mathbf{5 0 - 5 0 ~ 1}\end{array}$ & $\begin{array}{c}\text { Lethabo } \\
\mathbf{5 0 - 5 0 ~ 2}\end{array}$ & $\begin{array}{c}\text { Lethabo } \\
\mathbf{5 0 - 5 0 ~ 3}\end{array}$ \\
\hline Moisture [\%] & 35.68 & 40.15 & 44.08 \\
Density $\left[\mathrm{kg} / \mathrm{m}^{3}\right]$ & 1.564 & 1.499 & 1.453 \\
$\mathrm{Cw}[\%]$ & 64.32 & 59.86 & 55.92 \\
$\mathrm{Cv}[\%]$ & 47.00 & 41.58 & 37.75 \\
$\mathrm{pH}$ & 8.340 & 8.240 & 8.050 \\
$\mathrm{EC}[\mathrm{mS} / \mathrm{cm}]$ & 2.000 & 3.140 & 3.290 \\
$\tau_{\mathrm{y}}[\mathrm{Pa}]$ & 3.55 & 2.03 & 1.33 \\
$\mathrm{~K}\left[\mathrm{~Pa} . \mathrm{s}^{\mathrm{n}}\right]$ & 0.013 & 0.0070 & 0.0050 \\
$\mathrm{n}$ & 1.000 & 1.000 & 1.000 \\
\hline
\end{tabular}




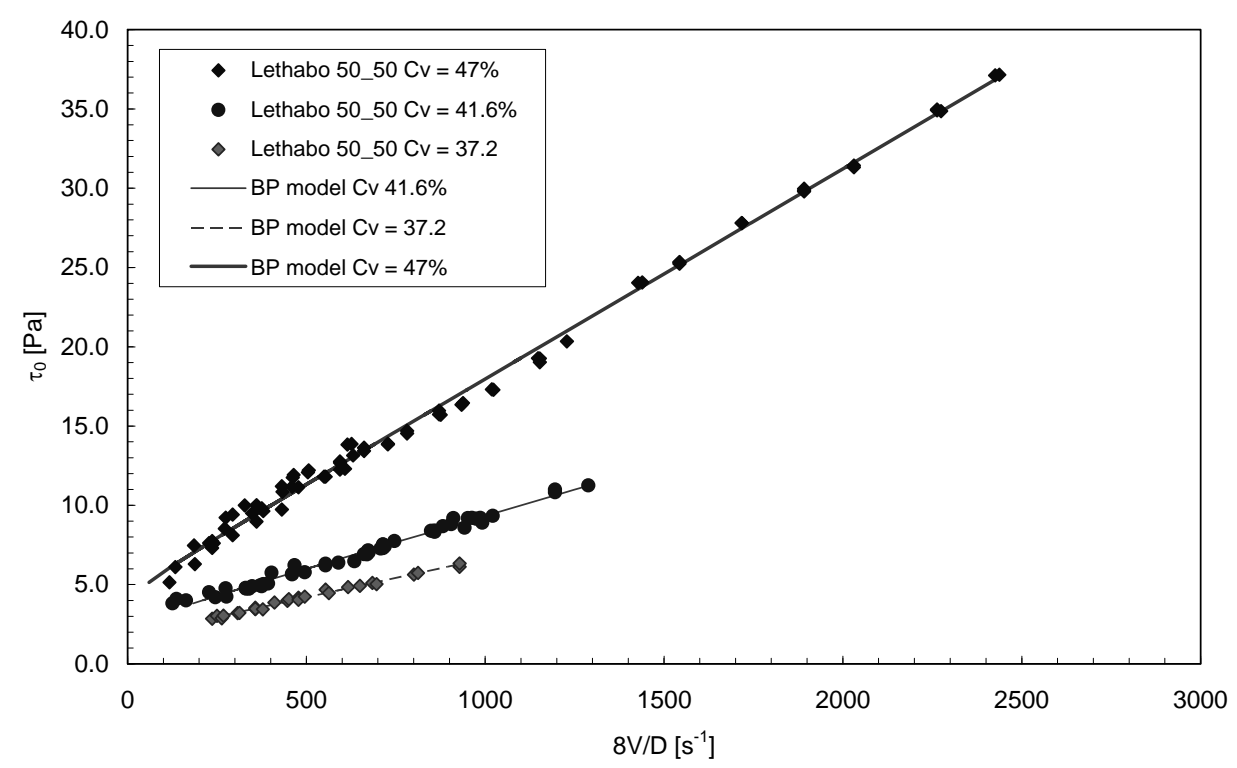

Figure 7 Pseudo-shear diagram for Lethabo Pozzfill/Superpozz (50/50) ash slurries

\subsection{Superpozz $100 \%$}

A $100 \%$ Superpozz slurry was tested next. The slurry properties are given in Table 7 . In this case, 98\% was less than $20 \mu \mathrm{m}$. The fines fraction was increased from 59 to $98 \%$ compared to the Pozzfill/Superpozz $50 / 50$ mixture. The $d_{50}$ was changed from 65 to $16 \mu \mathrm{m}$. In order to change only one parameter at a time, it was attempted to prepare the same concentrations as for the Pozzfill $100 \%$ slurry. It displayed Bingham plastic behaviour (Figure 8). The yield stress for the maximum concentration was only 3.5 Pa.

\section{Table 7 Lethabo Superpozz ash properties}

\begin{tabular}{lccc}
\hline Property & Superpozz 1 & Superpozz 2 & Superpozz 3 \\
\hline Moisture [\%] & 37.75 & 42.01 & 46.03 \\
Density [kg/m $\left.{ }^{3}\right]$ & 1.566 & 1.507 & 1.458 \\
$\mathrm{Cw}[\%]$ & 62.25 & 57.99 & 53.97 \\
$\mathrm{Cv}[\%]$ & 47.17 & 42.25 & 38.17 \\
$\mathrm{pH}$ & 8.250 & 8.050 & 8.020 \\
$\mathrm{EC}[\mathrm{mS} / \mathrm{cm}]$ & 1.930 & 2.120 & 2.350 \\
$\tau_{\mathrm{y}}[\mathrm{Pa}]$ & 3.65 & 1.32 & 0.572 \\
$\mathrm{~K}\left[\mathrm{~Pa} . \mathrm{s}^{\mathrm{n}}\right]$ & 0.013 & 0.0090 & 0.0070 \\
$\mathrm{n}$ & 1.000 & 1.000 & 1.000 \\
\hline
\end{tabular}




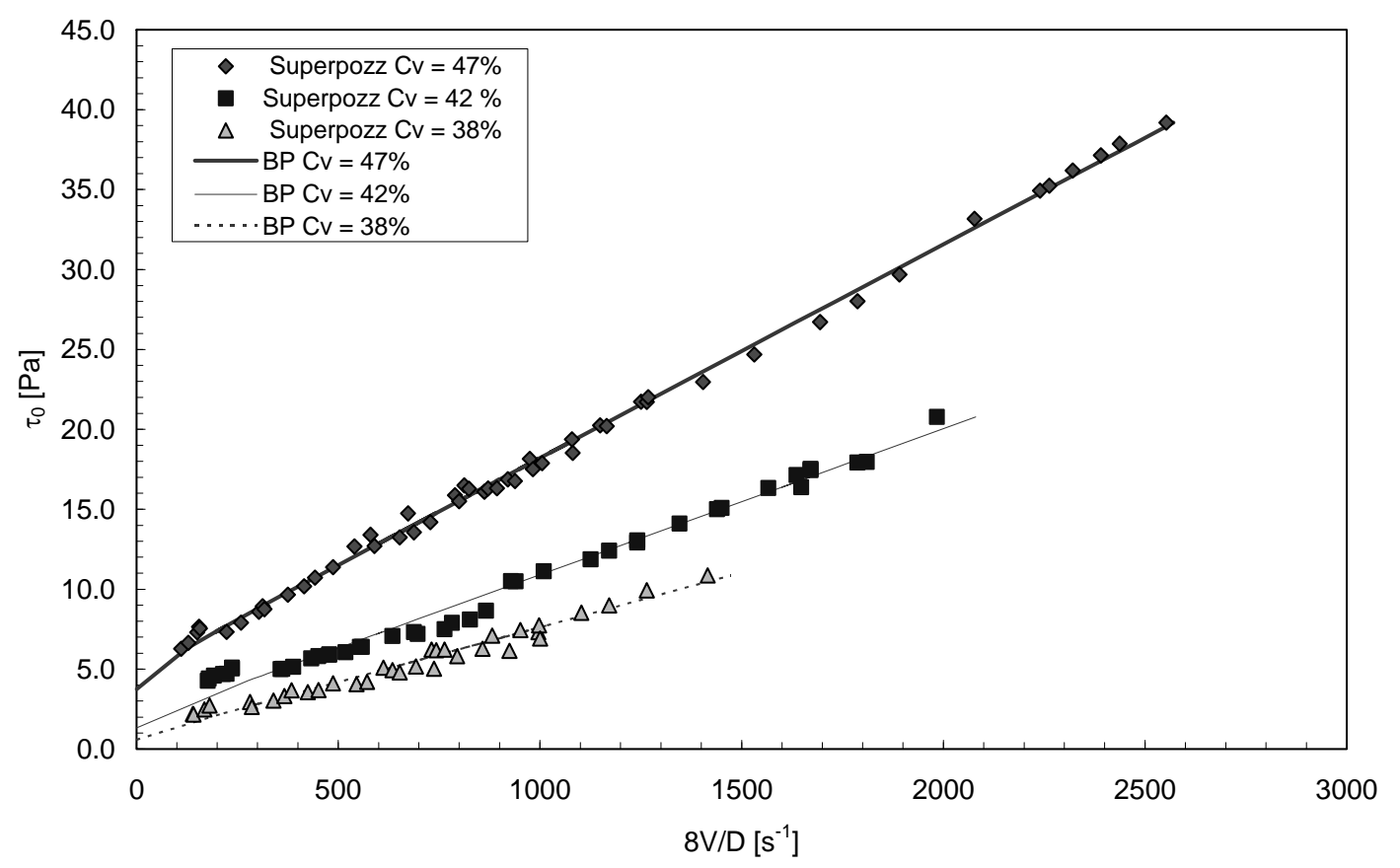

Figure 8 Pseudo-shear diagram for Lethabo Superpozz (100\%) ash slurries

\section{Comparison of results and conclusions}

It is expected that the viscosity of slurries will decrease with increasing $d_{50}$ (Heywood et al., 1993). It is also claimed that the finest fraction of the particle size distribution dominates the non-Newtonian behaviour of slurries (Iyer and Stanmore, 2000). Hanks and Hanks (1982) suggested that slurry can be considered to consist of discrete coarse solids suspended in a continuous vehicle of water and fine solids. For FA, the fine fraction is considered to be the fraction less than $10 \mu \mathrm{m}$ and greater than $10 \mu \mathrm{m}$ as coarse (Iyer and Stanmore, 1999). They also found that the addition of fines increased the yield stress. This effect was evaluated for the Lethabo ash. The results are given in Figure 9 to 11. For the higher concentrations above $\mathrm{C}_{\mathrm{v}}=40 \%$, it is clear that the Pozzfill slurry with the highest $\mathrm{d}_{50}(65 \mu \mathrm{m})$ has higher viscosities that those the 50/50 mix and Superpozz - with lower $d_{50}$ values (16 and $6 \mu \mathrm{m}$ respectively). At $C_{v}<40 \%$, this behaviour is not evident. The Pozzfill slurry with a slightly higher concentration has the same viscosity as the other two with a concentration of 38\%. This behaviour is inconsistent with the literature, which suggests that, by increasing the particle size and size distribution, the viscosity will be decreased. This work shows that for the FA tested, this is not so. For ash from two different power stations, with different base rheological behaviours, one Bingham and the other yield pseudoplastic, an increase in the viscosity occurred with the addition of a significant percentage of coarse particles using both rotational and tube viscometry. 


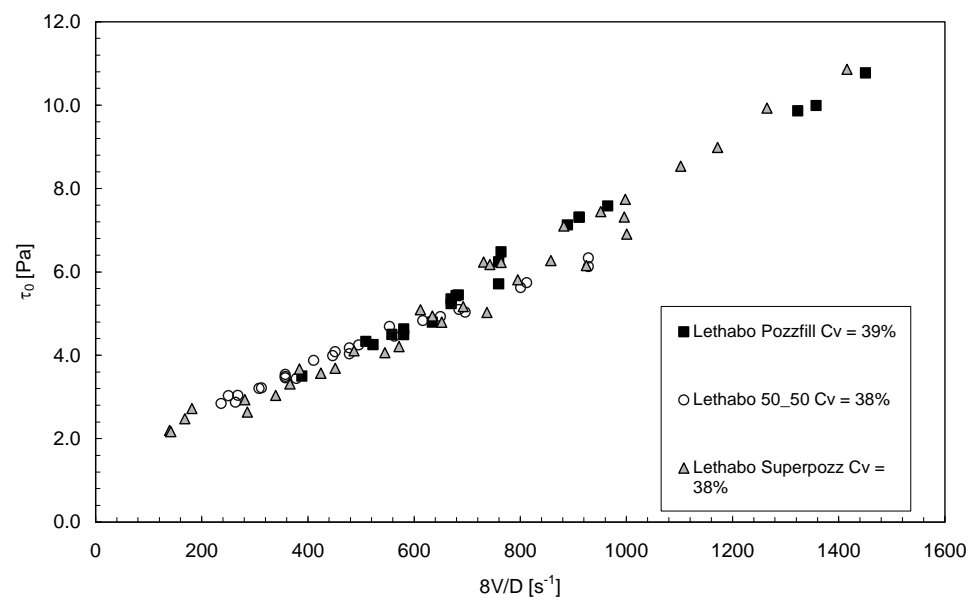

Figure 9 Comparison of Lethabo ash at $\mathrm{C}_{\mathrm{v}}=38 \%$

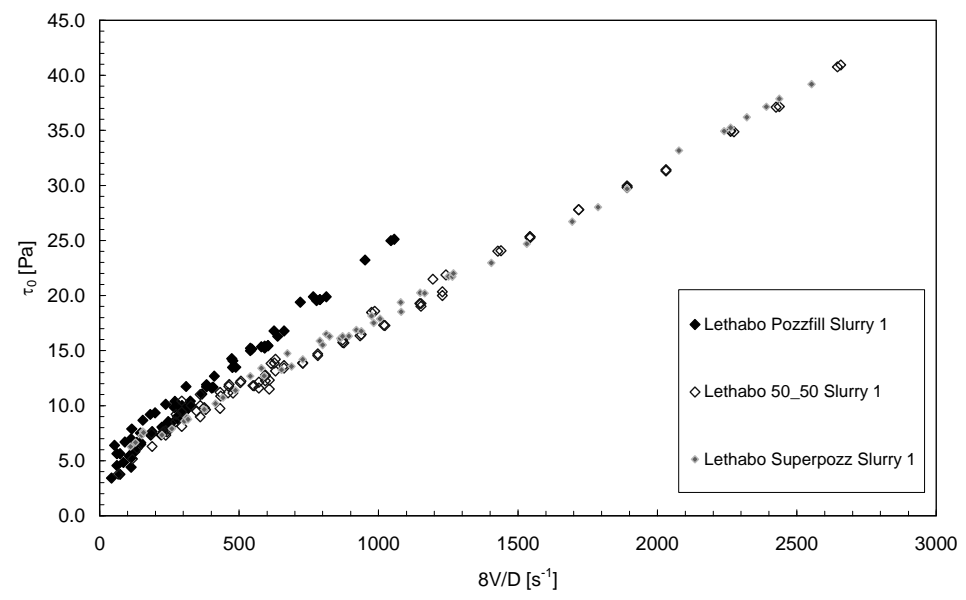

Figure 10 Comparison of Lethabo ash at $C_{v}=47 \%$

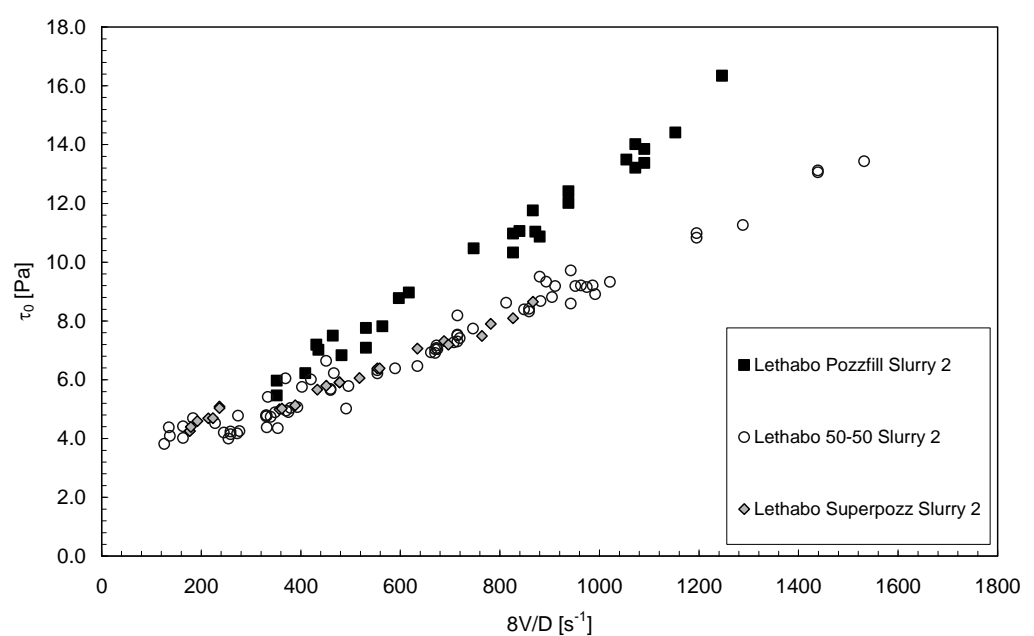

Figure 11 Comparison of Lethabo ash at $C_{v}=41 \%$ 
The neutralisation process reduced the $\mathrm{pH}$ of the FA slurries to 8 which enabled testing of the rheology of the slurries in a stable chemical environment. This process will be extended to control the $\mathrm{pH}$ at any level so that systematic studies of both the effect of chemistry and particle size can be observed. Since this work was done after a neutralisation process, it was assumed that any chemical effects had stabilised, and that the effect of particle size and size distribution was the dominant mechanism. The next series of tests will be conducted preparing slurries at different $\mathrm{pH}$ values and this can easily be done by controlling the neutralisation time. Figure 12 shows that although the there was some breakdown of larger particles (larger than $100 \mu \mathrm{m}$ ), there was not a significant increase in the fines fraction that could be the cause for the increase in the viscosity.

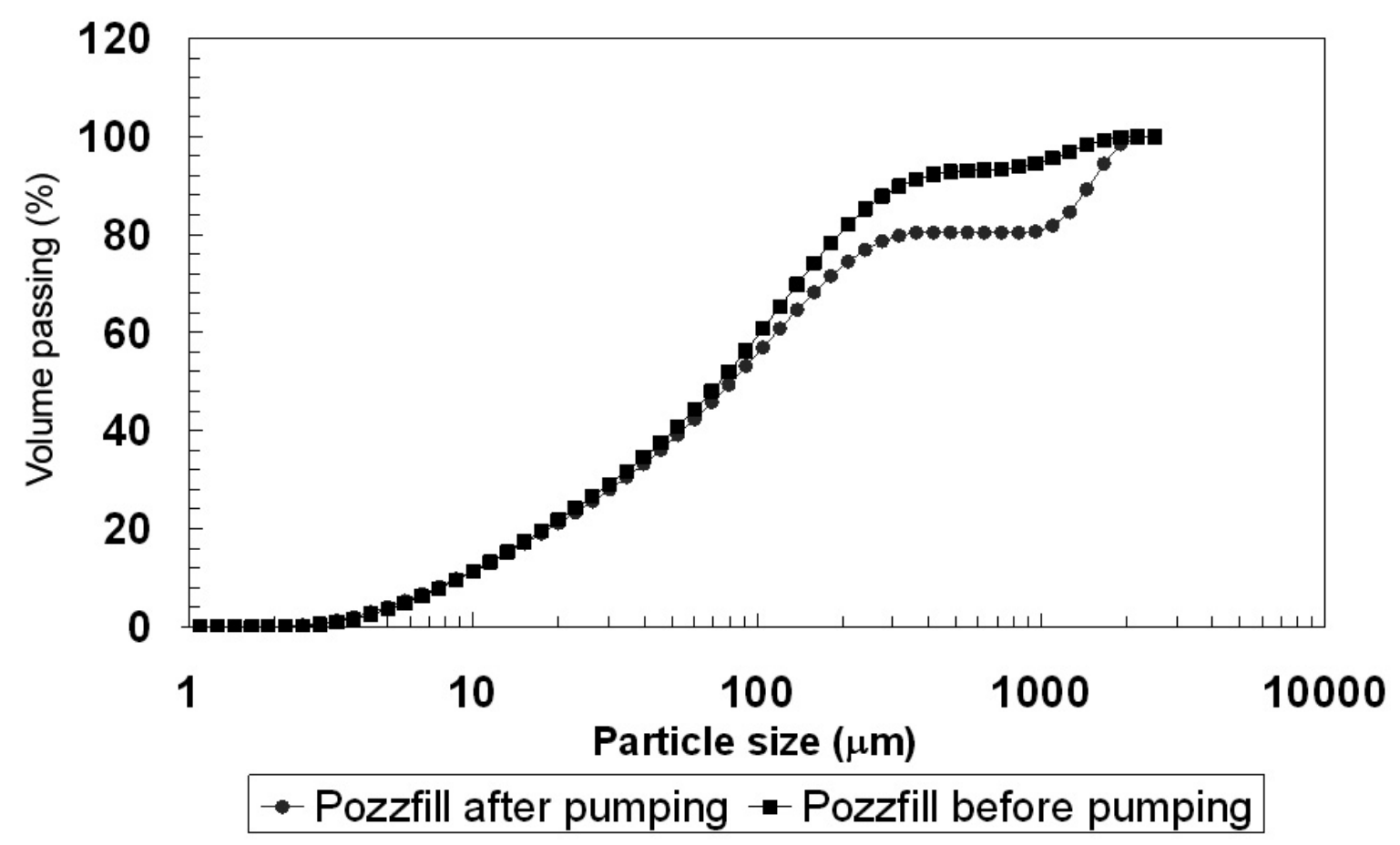

\section{Figure 12 Comparison of PSD of Pozzfill slurry before and after pumping}

In conclusion, this work shows that the presence of coarser particles at significant concentrations has an adverse effect on the neutralisation process as well as the pipe frictional losses that will be experienced during back fill operations, and needs to be taken into account.

\section{Acknowledgements}

The authors would like to thank Eskom for providing the financial assistance as well as for the use of their premises to conduct test work. We would also like to thank Richard du Toit, Hendrik Thomas and Marvin Antonie for assisting with test work. Financial assistance provided by WRC, Coaltech 2020 and Claude Leon Foundation is greatly appreciated. Finally, thanks are due to Richard Kruger for his untiring efforts to secure the ash for the trials.

\section{References}

Bournonville, B. and Nzihou, A. (2002) Rheology of non-Newtonian suspensions of fly ash: effect of concentration, yield stress and hydrodynamic interactions. Powder Technology 128, pp. 148-158.

Carlson, C.L. and Adriano, D.C. (1993) Environmental Impacts of Coal Combustion Residues. J. Environ. Qual. 22, pp. 227-247.

Cyr, M., Legrand, C. and Mouret, M. (2000) Study of shear thickening effect of superplasticizers on the rheological behaviour of cement pastes containing or not mineral additives. Cement and Concrete Research. 30, pp. 14771483.

Eskom Annual Report (2001) South Africa. 
Gitari, M.W., Petrik, L.F., Etchebers, O., Key, D.L., Iwuoha, E. and Okujeni, C. (2006) Treatment of acid mine drainage with fly ash: removal of major contaminants and trace elements. J Environ Sci Health A Tox Hazard Subst Environ Eng. 41(8), pp. 1729-1747.

Hakan, A., Oren, A.H. and Kaya, A. (2006) Factors effecting adsorption characterstics of Zn+2 on two natural zeolites. Journal of Hazardous Materials. 131, pp. 59-65.

Hanks, R.R. and Hanks, K.W. (1982) A new viscometer for determining the effect of particle size distributions and concentration on slurry rheology, 7th International Technical Conference on Slurry Transportation, Lake Tahoe, NV, USA.

Heywood, N.I., Mehta, K. B. and Poplar, D. (1993) Assessment of flow properties of pulverized fuel ash slurries at high concentration. Proceedings 12th International Conference on Slurry Handling and Pipeline Transport: Hydrotransport 12, 28-30 September 1993, Brugge, Belgium, edited by C.A. Shook. London: Mechanical Engineering Publications.

Iyer, R.S. and Stanmore, B. (1999) The effect of water absorption and the role of fines on the yield stress of dense fly ash slurries. Cement and Concrete Research 29, pp. 765-767.

Iyer, R.S. and Stanmore, B. (2000) The distortion of the diffuse double layer and its effects on flow properties of dense flyash slurries. Colloids and Surfaces A: Physiochemical and Engineering Aspects 166, pp. 133-144.

Komnitsas, K., Bartzas, G. and Paspaliaris, I. (2004). Clean up of acidic leachates using fly ash barriers: Laboratory column studies. Global Nest: The International Journal, 6(1), pp. 81-89.

Olhero, S.M. and Ferreira, J.M. (2004). Influence of particle size distribution on rheology and particle packing of silicabased suspensions. Powder Technology 139, pp. 69-75.

Petrik, L., Gitari, M.W., Vadapalli, V.R.K., Etchebers, O., Ellendt, A., Reynolds, K., Surender, D., Hendricks, N., Klink, M.J., Somerset, V.S., White, R.A., Burgers, C., Key, D.L. and Iwouha, E.I. (2006a). Applications of ash and its derivates: water treatment, mine backfilling, lining and walling. 13th International Conference Ashes from Power Generation, 6-8 November, Krakow, Poland.

Petrik, L., Burgers, C., Gitari, W., Surender, D., Reynolds, K., Ellendt, A., Etchebers, O., Vadapalli, V.R.K., Key, D. and Iwuoha, E. (2006d) Stability and Neutralisation capacity of Potential Mine Backfill Material Formed by Neutralisation of Fly Ash and Acid Mine Drainage. Final Report submitted to Water Research Commission, K5/1458, South Africa.

Razo, I., Carrizales, L., Castro, J., Diaz-Barriga, F. and Monroy, M. (2004) Arsenic and Heavy Metal Pollution of Soil, Water and Sediments in a Semi-Arid Climate Mining Area in Mexico. Water, Soil and Air Pollution, 152, pp. 129-152. 